\title{
Acute Pulmonary Embolism and 1-Year Outcome: An Epidemiological Study in East of Iran, 2011-2016
}

\author{
Mohammad Reza Ghasemian Moghaddam (id ${ }^{1,2}$, Nahid Azdaki (id ${ }^{1,2,{ }^{*}}$ and Mohammad Sadegh \\ Ghasemi (iD ${ }^{3}$ \\ ${ }^{1}$ Cardiovascular Diseases Research Center, Birjand University of Medical Sciences, Birjand, Iran \\ ${ }^{2}$ Razi Clinical Research Development Unit (RCRDU), Birjand University of Medical Sciences, Birjand, Iran \\ ${ }^{3}$ Student Research Committee, Birjand University of Medical Sciences, Birjand, Iran \\ "Corresponding author: Atherosclerosis Research Center, Birjand University of Medical Sciences, Birjand, Iran. Tel: +98-5632381254, Fax: +98-5632381256, Email: \\ nahidazdaki@yahoo.com
}

Received 2019 June 11; Revised 2019 September 17; Accepted 2019 September 25

\begin{abstract}
Background: Pulmonary thromboembolism (PTE) is a major health problem worldwide. The present study was conducted to investigate epidemiology of acute PTE and its outcomes in Birjand city, locating in South Khorasan, Iran.

Methods: In this descriptive epidemiological study, 79 patients with PTE referred to Vali-Asr Hospital, Birjand, Iran were studied during 2011 - 2016. In this study, demographic data, medical history, risk factors, symptoms, and information on diagnostic methods including echocardiography findings, electrocardiographic findings, treatment procedure, duration of hospitalization, and therapeutic outcomes were collected in information form for each patient. One year later, the patients were re-visited, and echocardiography was performed for all the subjects. Finally, data were analyzed by Chi-Square and Fisher's exact tests at a significant level of 0.05 using SPSS software.

Results: Results showed that annual incidence of PTE was 5.7 per 100,000 people in Birjand in 2016. History of recent surgery (18.8\%) followed by hospitalization, and complete bed rest for more than 3 days (15.7\%) were the most common risk factors. More than $78 \%$ of patients with PTE had abnormal echocardiography, and pulmonary arterial hypertension was the most common finding. Results of statistical analysis showed that complications were not statistically significant according to age and gender of patients $(\mathrm{P}<0.05)$, but complications were higher in patients with massive PTE compared to others $(\mathrm{P}=0.01)$. Comparison of in-hospital complications showed a significant difference between different treatment modalities $(\mathrm{P}<0.01)$.

Conclusions: History of recent surgery and hospitalization were the most common predisposing factors for PTE. Therefore, necessary programs should be more vigorously pursued for prevention of PTE.
\end{abstract}

Keywords: Pulmonary Thromboembolism, Prevalence, Birjand

\section{Background}

Venous thromboembolism (VTE) includes deep vein thrombosis (DVT) and pulmonary thromboembolism (PTE) that are major concerning diseases worldwide. VTE is associated with serious short and long-term complications, even death (1). VTE imposes a major global burden with about 10 million cases occurring per year, which is the third leading vascular disease after myocardial infarction (MI) and cerebrovascular accident (2). Just 300,000 PTE cases occur every year in six European countries with 300 million inhabitants and the incidence is continuously increasing each year because of the aging phenomenon, higher prevalence of other associated comorbidities such as obesity, heart failure, cancer, surgical procedure, pregnancy, and improvement of diagnostic tools $(2,3)$. On the other hand, PTE is one of the most preventable causes of death among hospitalized patients (4). Studies revealed that about $20 \%$ of patients with PTE still die before diagnosis and shortly thereafter, especially in massive PTE in association with hemodynamic instability (2). In addition to acute side effects, the sequels of PTE are also associated with serious disability such as chronic pulmonary hypertension, which complicates between 0.6 and $8.8 \%$ of PTE cases $(5,6)$. Therefore, making an early diagnosis, identifying predictors, and selecting the best therapeutic strategies are very important (6).

Currently, there are three main therapeutic options for PTE including heparin therapy, thrombolytic therapy, and surgical embolectomy, which could be used according to the patient's condition $(7,8)$. However, the best therapeutic

Copyright (c) 2019, Modern Care Journal. This is an open-access article distributed under the terms of the Creative Commons Attribution-NonCommercial 4.0 International License (http://creativecommons.org/licenses/by-nc/4.0/) which permits copy and redistribute the material just in noncommercial usages, provided the original work is properly cited. 
strategy is controversial and more evaluations in this field are needed $(2,9)$. Diagnostic tools and therapeutic procedures are improving but for better recognition of PTE, complementarity studies are needed.

\section{Objectives}

According to the above, this study aimed to investigate the epidemiology of acute PTE and its outcomes based on the severity of PTE and the type of treatment in Birjand city.

\section{Methods}

In this descriptive-epidemiological study, we evaluated 79 patients with PTE diagnosis referring to Vali-e-Asr Birjand Hospital in 2011 - 2016. The sampling method was census to select all patients with acute pulmonary embolism admitted to the hospital setting during the study period from among those who met the inclusion criteria (definitive diagnosis of pulmonary embolism as the main cause of symptoms). The exclusion criteria included dissatisfaction and incomplete medical records. In this study, demographic data, medical history, predisposing factors, symptoms, and diagnostic methods information including echocardiographic findings (GE, cardiac ultrasound systems, Vivid 7, Vingmed, Horten, Norway) and electrocardiographic (ECG) findings, treatment procedure, duration of hospitalization, and therapeutic outcomes were collected in information forms for each patient. One year after admission, the patients were re-visited and echocardiography was performed by a cardiologist. Then, major risk factors for PTE were investigated according to patients' information, including the history of previous illnesses such as pregnancy, active cancer, hypertension (HTN), ischemic heart disease (IHD), dyslipidemia (DLP), diabetes mellitus (DM), paresis or plegia, hospitalization or complete bed rest for more than three days, history of abdominal surgery, orthopedic surgery and obstetric surgery in recent 12 weeks, fractures of the lower limbs, and oral contraceptives (OCP) or hormone replacement therapy (HRT). Patients with these conditions were categorized as provoked and patients that were not included in this category were classified as unprovoked (10). Finally, data were analyzed by SPSS version 16 software (Chicago, IL, USA) using the chisquare and Fisher exact tests at a significant level of 0.05 .

\section{Results}

Statistical analysis showed that the patients' mean age was $56.13 \pm 17.81$. The sample included $56.9 \%$ of males and $43 \%$ of females. The annual PTE incidence in Birjand in
2016, based on the population of the city in the same year and the rate of new cases, was 5.7 per 100,000 population. Also, the results of statistical analysis showed that $68.30 \%$ of the patients were in the provoked group and $31.70 \%$ were in the unprovoked group. Abdominal surgery, orthopedic surgery, and obstetric surgery with the frequency of $18.8 \%$ were the most common risk factors for PTE among patients, followed by hospitalization and complete resting for more than three days with $15.7 \%$ (Figure 1). In addition, acute dyspnea was the most common symptom among patients with a frequency of $25.4 \%$ (Figure 2).

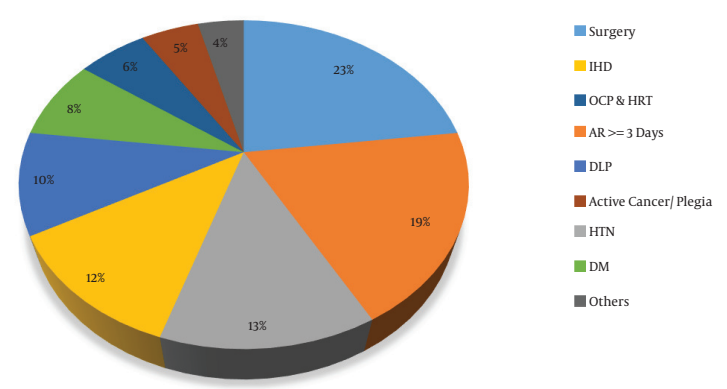

Figure 1. The frequency of risk factors. Surgery, abdominal, orthopedic, and obstetrics; AR, absolute rest; HTN, hypertension; IHD, ischemic heart disease; DLP, dyslipidemia; DM, diabetes mellitus; OCP \& HRT, oral contraceptive and hormone replacement therapy; others, pregnancy, lower limb fracture, smoking, COPD, past history of DVT.

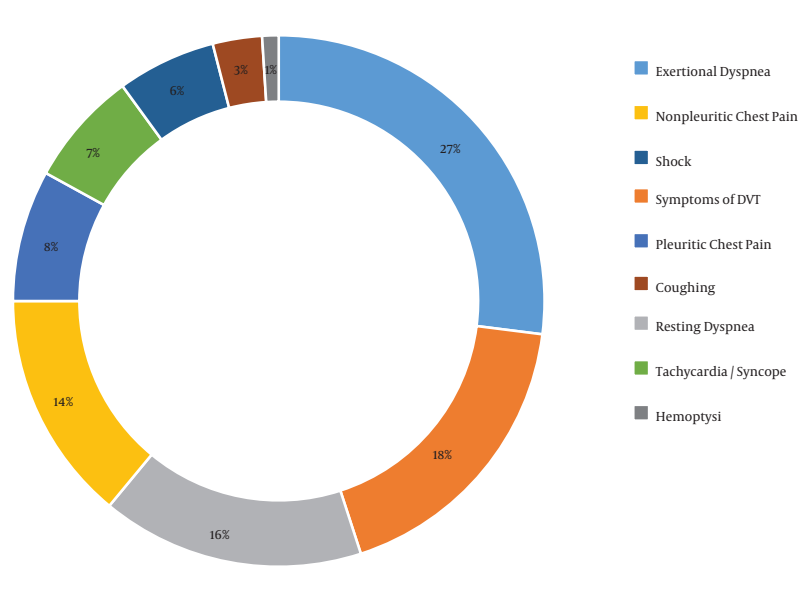

Figure 2. The frequency of symptoms

Trans-thoracic echocardiographic findings revealed right ventricular enlargement in 56 (70.9\%) patients. Also, 41 (51.9\%) patients had right ventricular dysfunction and a blood clot in the right heart was seen in 3 (3.9\%) patients. Moreover, 61 (78.5\%) patients had tricuspid regurgitation; McConnell's sign was seen in 13 (16.5\%) patients while 65 (77.2\%) patients had pulmonary arterial hyperten- 
sion (PAH) with a mild severity in $18(28.1 \%)$ patients, moderate severity in 24 patients (37.5\%), and high severity in 22 (34.3\%) cases (Table 1). ECG changes in the early stages of acute PTE are shown in Table 1, which showed 12 (15.5\%) patients had no evidence of PTE in their primary ECG.

Table 1. Frequency of Echocardiographic and Electrocardiographic Findings on Admission

\begin{tabular}{|lc|}
\hline & Frequency, \% \\
\hline A) Echocardiographic findings & 65 \\
\hline Pulmonary artery hypertension & 61 \\
\hline Tricuspid regurgitation & 56 \\
\hline Right ventricle enlargement & 41 \\
\hline Right ventricle dysfunction & 13 \\
\hline McConnell's sign & 3 \\
\hline Blood clot in right heart chambers & \\
\hline B) Electrocardiographic findings & 45 \\
\hline Sinus tachycardia & 44 \\
\hline Inverted T wave in lead III & 30 \\
\hline Q wave in lead III & 19 \\
\hline Inverted T wave in pericardial lead/S wave in lead I & 13 \\
\hline Normal ECG & 8 \\
\hline Right axis deviation & 7 \\
\hline Right bundle branch block & 1 \\
\hline Atrial fibrillation & \\
\hline
\end{tabular}

Echocardiography was the only imaging method in 13 patients because of pregnancy, unstable hemodynamic status, advanced renal failure, and the death of the patient before the opportunity to perform more accurate diagnostic procedures. Diagnosis of 59 patients was done by pulmonary artery CT angiography (CTPA) and 7 patients with lung perfusion-ventilation scans. Based on symptoms such as the presence or absence of syncope or obstructive shock, echocardiographic findings such as the presence or absence of dysfunction or increased right ventricle size and the positive or negative troponin I (TnI), patients with acute PTE were divided into three groups: small, submassive, and massive (11). In the small PTE group, there was no syncope or obstructive shock; in echocardiography, the size of the right ventricle was not increased and TnI was negative. Submassive PTE was associated with right ventricle size increase, right ventricular dysfunction, and positive TnI. The manifestation of the disease with syncope or obstructive shock indicated the massive nature of the disease. Accordingly, a total of 19 (24.1\%) patients were in the small PTE group, 42 (51.8\%) patients in the submassive PTE group, and 18 (24\%) patients in the massive PTE group.

Three main therapeutic methods for acute PTE in- cluded anticoagulant therapy, fibrinolytic therapy, and surgical embolectomy (12). Therefore, 52 (65.8\%) patients were treated with heparin, 16 (20.3\%) patients with streptokinase, and 11 (13.9\%) patients with surgical embolectomy. All patients with small PTE were treated with heparin. Among patients with submassive PTE, 28 patients were treated with heparin, 12 patients with streptokinase, and 2 patients with surgery. In massive PTE, 9 patients were treated with surgical embolectomy, 5 patients with heparin, and 4 patients with streptokinase.

The findings showed that the mean hospitalization duration was 8.9 days, with a minimum hospital stay of 4 days and a maximum of 42 days. There were 71 patients discharged with complete or relative improvement and no complications. Three patients died, one patient left the hospital by her own consent, and four patients receiving streptokinase suffered from complications during the hospitalization, leading to final discharge by partial or complete recovery. All of the patients who died were in the massive PTE group, which undergone embolectomy with a mean age of 53 years.

The results of the chi-square test showed that inhospital complication, bleeding, and mortality did not statistically significantly changed according to the age of patients $(\mathrm{P}=0.69)$. Also, the changes in the relative frequency of complications, bleeding, and mortality were not statistically significant according to gender $(\mathrm{P}=0.906)$. The comparison of complications in terms of the severity of thromboembolic events showed that complications in patients with massive PTE were more than those in other groups $(\mathrm{P}=0.01)$ (Table 2$)$. In addition, the difference in inhospital complications was significant between different treatment modality groups $(\mathrm{P}<0.01)$ (Table 2$)$.

After at least one year, 39 out of 79 patients were followed up. Of these, 11 (28.2\%) patients died after discharge from the hospital during this period, seven of whom were in the submassive PTE group and four in the massive PTE group. Accordingly, 28 patients were alive and echocardiography was performed for 11 patients, which was normal, except for two patients from the massive group who were over the age of 70. In their echocardiography, there was an increase in pulmonary arterial pressure and right ventricular dysfunction; in fact, there was evidence of right ventricular failure as a long-term complication of acute PTE. There was also exceptional dyspnea in nine patients, seven of whom had functional class II (FC-II) dyspnea and two had FC-III dyspnea. Of these patients, five were in the submassive PTE group, three were in the small PTE group, and one was in the massive PTE group. 


\begin{tabular}{|c|c|c|c|c|c|}
\hline Variables & Categories & $\begin{array}{c}\text { Without } \\
\text { Complications }\end{array}$ & Hemorrhagic Events & Mortality & PValue \\
\hline \multirow{3}{*}{ Age, $y$} & $>40$ & $18(94.7)$ & $1(5.3)$ & - & \multirow{3}{*}{0.692} \\
\hline & $41-59$ & $22(84.6)$ & $2(7.7)$ & $2(7.7)$ & \\
\hline & $<60$ & $31(94)$ & $1(3)$ & $1(3)$ & \\
\hline \multirow{2}{*}{ Gender } & Male & $41(91.1)$ & $2(4.4)$ & $2(4.4)$ & \multirow{2}{*}{0.906} \\
\hline & Female & $30(90.9)$ & $2(6.1)$ & $1(3)$ & \\
\hline \multirow{3}{*}{ Severity } & Small & $19(100)$ & - & - & \multirow{3}{*}{0.013} \\
\hline & Submassive & $39(95.1)$ & $2(4.9)$ & - & \\
\hline & Massive & $13(72.2)$ & $2(11.1)$ & $3(16.7)$ & \\
\hline \multirow{3}{*}{ Treatment } & Heparin & $52(100)$ & - & - & \multirow{3}{*}{0.001} \\
\hline & Fibrinolytic & $12(75)$ & $4(25)$ & - & \\
\hline & Embolectomy & $7(70)$ & - & $3(30)$ & \\
\hline
\end{tabular}

${ }^{\mathrm{a}}$ Values are expressed as No. (\%).

\section{Discussion}

This study aimed to investigate the epidemiology of acute PTE and its outcomes in Birjand city. The results showed that the annual incidence of PTE was 5.7 per 100,000 population in Birjand city in 2016. In a study by Horlander et al. (13), the annual incidence of PTE was 100 per 100,000 population in the USA in 2003. In addition, the annual incidence of PTE in Portugal was 35 per 100,000 population in 2013 (14). Although there are some studies in this field around the world, there was no similar study in Iran. The incidence rate reported in our study was based on the cases of PTE hospitalized in Birjand Vali-e-Asr Hospital. Undoubtedly, there were other cases of PTE diagnosed at other regional medical centers, but because of reasons such as patient's death, they were not considered. On the other hand, there is a considerable difference in PTE incidence between different races; moreover, Asian countries have lower incidence rates than American and European countries, which can justify our results $(13,15)$. Our results showed that men had a higher rate of PTE and mortality than women but the difference was not significant. Due to the low sample size, especially at the followed-up stage, this result cannot be considered, but similar studies, such as a study by Horlander et al. in 2003, reported the same results (13).

In this study, the most common comorbidity was hypertension, followed by ischemic heart disease, dyslipidemia, and diabetes. Also, the most common risk factor for pulmonary embolism was a history of surgery in less than 12 weeks ago, followed by hospitalization or resting for more than three days and OCP or HRT, which are similar to the results of many other studies $(16,17)$. In addition, the most common symptoms were dyspnea, followed by chest pain, which is similar to other study results $(16,17)$.

TnI was positive in $18 \%$ of the evaluated cases, all of whom were in the massive and submassive groups. In a similar study, positive TnI was reported in 55\% of patients with a definite diagnosis of acute PTE (18), which is higher than the rate obtained in this study. In another study in 2012, TnI was positive in 50\% of patients (19). The reason for the lower positive TnI rate in this study is that TnI was not measured for all patients and perhaps the sensitivity of laboratory methods was lower in this study than in similar studies.

More than $78 \%$ of patients with PTE had abnormal echocardiography and the most common findings were $\mathrm{PAH}$, tricuspid regurgitation, hypertrophy, and right ventricular dysfunction. In a study conducted by Ouldzein et al. in 2009 (20), the most common echocardiographic findings in patients with a definite diagnosis of acute PTE were right ventricular enlargement and elevated pulmonary arterial pressure. In another study by Stawicki et al. in 2008 (21), the most common echocardiographic findings of acute PTE were tricuspid regurgitation (90\%), PAH (77\%), right ventricular enlargement (74\%), right ventricular stretch (61\%), and hyperdynamic left ventricle (54\%), which are similar to our findings.

Statistical analysis also revealed that the most common ECG findings were sinus tachycardia, the $S$ wave in lead I, the inverted T wave in lead III, and the $\mathrm{Q}$ wave in lead III. In a similar study (22), the most common ECG finding of the acute PTE was sinus tachycardia (38\%), followed by the reverse T wave in V1 (38\%) and ST-segment elevation (36\%) in the aVR lead. In addition, in Ryu et al. (23) study, the 
most common ECG findings were sinus tachycardia and reverse T wave in V1 to V4 leads. In another similar study (24), the most common findings of ECG in acute PTE were sinus tachycardia, inverted T wave in lead III, aVF, and pre-cordial leas. In a study by Bakebe et al. (25), the most common findings of ECG in acute PTE were sinus tachycardia (72\%), the S wave in lead I, the inverse $\mathrm{T}$ wave in lead III and the $\mathrm{Q}$ wave in lead III (30\%), and the reverse T wave in V4-1 (34\%). These data are similar to our findings in this study.

CTPA was the most common diagnostic method in our study. In order to diagnose PTE, the most commonly used imaging technique was CTPA, followed by echocardiography and a nuclear scan. CTPA is the imaging method of choice for the diagnosis of acute PTE (26) and it has been used as the most common method for diagnosis because of its availability, fastness, and high sensitivity and specificity (27). In addition, this method is selective in patients who are suspected of PTE and are in a stable hemodynamic status.

All cases of in-hospital mortality were related to patients with massive PTE. This difference was statistically significant and indicated the association between the severity of the disease and in-hospital mortality, which is similar to other study findings $(28,29)$. In addition, there were no significant differences in acute complications between three groups of age. Old age is a predisposing factor for PTE (30) and worse outcome (31). Although our findings showed that the older age group was related to more complications, there was no significant association between age and complications that may be justified by the low number of participants. There was no significant difference in acute complications between gender groups that is in line with previous studies (32). Our findings revealed that there was a significant difference between acute mortality of PTE and its severity so that the massive group had more acute complications and mortality. These findings are similar to similar studies (7) and implies that the severity of PTE plays an important role in prognosis. Our findings showed that the type of treatment method was associated with a specific acute complication so that thrombolytic therapy significantly increased hemorrhagic events and embolectomy was associated with higher mortality. Previous studies showed that thrombolytic therapy was associated with more hemorrhagic events because of its effect (33-35). In addition, because of the severity of PTE in patients treated with embolectomy, a higher mortality rate was expected. Also, one-year mortality occurred only in the massive and submassive groups and none of the patients in the small PTE group died during hospitalization or at one-year follow-up. All bleeding events occurred in streptokinase-treated patients; of course, none of them was life-threatening. The right ventricular failure occurred only in the massive group. These findings revealed the relationship between the severity, complications, and mortality, which is in line with similar studies $(11,28,36,37)$.

All patients in the small PTE group were treated with heparin. Heparin is the most commonly used treatment agent for submassive cases (12). The most common treatment used for massive embolism is embolectomy (35). Of course, the preferred method of treatment in massive cases is fibrinolytic therapy, but due to the absolute prohibition of fibrinolytic therapy, embolectomy was used in most cases of massive PTE in this study (mostly due to the history of major surgery in patients).

Despite all the progress made, PTE still has a significant mortality rate $(1,25)$. More awareness of the clinical symptoms, risk factors, and clinical suspicion can help diagnose it as quickly as possible and reduce possible complications. Choosing the appropriate treatment and imaging exams varies depending on the condition of each patient.

\subsection{Conclusions}

According to the results, the most common predisposing factors for PTE in Birjand are the history of recent surgery in less than 12 weeks ago and hospitalization or resting for more than three days. Therefore, the necessary programs for the prevention of DVT and PTE should be more vigorously pursued in the hospital.

\section{Footnotes}

Authors' Contribution: Nahid Azdaki and Mohammad Reza Ghasemian Moghaddam were designing the project and supervision. Mohammad Sadegh Ghasemi did data acquisition, drafting of the manuscript in Persian, and revising the manuscripts in English. All authors read and approved the final manuscript.

Conflict of Interests: The authors declare no conflicts of interest, financial or otherwise, with regard to the study.

Ethical Approval: This study was approved by the Ethics Committee of the Birjand University of Medical Sciences, Birjand, Iran (ethical No.: Ir.bums.REC.1395.241).

Funding/Support: This study was funded by the Birjand University of Medical Sciences.

Informed Consent: Participants signed informed consent forms.

\section{References}

1. Raskob GE, Angchaisuksiri P, Blanco AN, Buller H, Gallus A, Hunt BJ, et al. Thrombosis: A major contributor to global disease burden. Thromb Res. 2014;134(5):931-8. doi: 10.1016/j.thromres.2014.08.014. [PubMed: 25312343]. 
2. Di Nisio M, van Es N, Büller HR. Deep vein thrombosis and pulmonary embolism. The Lancet. 2016;388(10063):3060-73. doi: 10.1016/s01406736(16)30514-1.

3. Grosse SD, Nelson RE, Nyarko KA, Richardson LC, Raskob GE. The economic burden of incident venous thromboembolism in the United States: A review of estimated attributable healthcare costs. Thromb Res. 2016;137:3-10. doi: 10.1016/j.thromres.2015.11.033. [PubMed: 26654719]. [PubMed Central: PMC4706477].

4. Gould MK, Wu YL, Liu A, Handler J, Lau H, Clarke A, et al. Incidence of venous thromboembolism Following major surgery: Opportunities for care improvement. J Patient Cent Res Rev. 2015;2(2):96-7. doi: 10.17294/2330-0698.1097.

5. Hoeper MM, Madani MM, Nakanishi N, Meyer B, Cebotari S, Rubin LJ. Chronic thromboembolic pulmonary hypertension. Lancet Respir Med. 2014;2(7):573-82. doi: 10.1016/s2213-2600(14)70089-x.

6. Akbayrak H, Tekumit H. Pulmonary thromboendarterectomy in a combined thrombophilia patient. Cardiovasc J Afr. 2019;30(1):e4-6. doi: 10.5830/CVJA-2018-052. [PubMed:30460973].

7. Meyer G, Vicaut E, Danays T, Agnelli G, Becattini C, Beyer-Westendorf $\mathrm{J}$, et al. Fibrinolysis for patients with intermediate-risk pulmonary embolism. N Engl J Med. 2014;370(15):1402-11. doi: 10.1056/NEJMoa1302097. [PubMed: 24716681].

8. Yilmazel Ucar E, Araz O, Kerget B, Yilmaz N, Akgun M, Saglam L. Comparison of long-term outcomes of 50 and $100 \mathrm{mg}$ rt-PA in the management of acute pulmonary thromboembolism. Clin Respir J. 2018;12(4):1628-34. doi: 10.1111/crj.12721. [PubMed: 29044967].

9. Nagamalesh UM, Prakash VS, Naidu KCK, Sarthak S, Hegde AV, Abhinay T. Acute pulmonary thromboembolism: Epidemiology, predictors, and long-term outcome - A single center experience. Indian Heart J. 2017;69(2):160-4. doi: 10.1016/j.ihj.2016.08.010. [PubMed: 28460762]. [PubMed Central: PMC5414948].

10. Ende-Verhaar YM, Cannegieter SC, Vonk Noordegraaf A, Delcroix M, Pruszczyk P, Mairuhu AT, et al. Incidence of chronic thromboembolic pulmonary hypertension after acute pulmonary embolism: A contemporary view of the published literature. Eur Respir J. 2017;49(2). doi: 10.1183/13993003.01792-2016. [PubMed: 28232411].

11. Cho YJ, Koo SM, Bang DW, Kim KU, Uh ST, Kim YK. Short-Term Mortality in Patients with Massive and Submassive Pulmonary Embolism Receiving Thrombolytic Therapy. Korean J Med. 2013;84(1):62. doi: 10.3904/kjm.2013.84.1.62.

12. Chen $\mathrm{H}$, Ren $\mathrm{C}$, Chen H. Thrombolysis versus anticoagulation for the initial treatment of moderate pulmonary embolism: A meta-analysis of randomized controlled trials. Respir Care. 2014;59(12):1880-7. doi: 10.4187/respcare.03197. [PubMed: 25269681].

13. Horlander KT, Mannino DM, Leeper KV. Pulmonary embolism mortality in the United States, 1979-1998: An analysis using multiple-cause mortality data. Arch Intern Med. 2003;163(14):1711-7. doi: 10.1001/archinte.163.14.1711. [PubMed: 12885687].

14. Gouveia M, Pinheiro L, Costa J, Borges M. [Pulmonary embolism in portugal: Epidemiology and in-hospital mortality]. Acta Med Port. 2016;29(7-8):432-40. Portuguese. doi: 10.20344/amp.6367. [PubMed: 27914153].

15. Meyer G, Planquette B, Sanchez O. Long-term outcome of pulmonary embolism. Curr Opin Hematol. 2008;15(5):499-503. doi: 10.1097/MOH.ob013e3283063a51. [PubMed: 18695374].

16. Belohlavek J, Dytrych V, Linhart A. Pulmonary embolism, part I: Epidemiology, risk factors and risk stratification, pathophysiology, clinical presentation, diagnosis and nonthrombotic pulmonary embolism. Exp Clin Cardiol. 2013;18(2):129-38. [PubMed: 23940438]. [PubMed Central: PMC3718593].

17. Stryjewski PJ, Krupa E, Janus B, Cubera T, Nessler B, Badacz L, et al. [Epidemiology of pulmonary embolism in patients with cardiac department]. Przegl Lek. 2011;68(9):588-91. Polish. [PubMed: 22335006].

18. Smith TA. The prognostic value of undetectable highly sensitive cardiac troponin I in patients with acute pulmonary embolism. J Emerg Med.2015;49(3):387-8. doi:10.1016/j.jemermed.2015.07.010.
19. Thielmann M, Pasa S, Wendt D, Price V, Marggraf G, Neuhauser M, et al Prognostic significance of cardiac troponin I on admission for surgical treatment of acute pulmonary embolism: a single-centre experience over more than 10 years. Eur J Cardiothorac Surg. 2012;42(6):951-7. doi: 10.1093/ejcts/ezs122. [PubMed: 22491666].

20. Ouldzein H, Rahal N, Cherradi R, Zouaoui W, Mechmeche R, Haouala $\mathrm{H}$. [Role of transthoracic echocardiography in the diagnosis of acute pulmonary embolism]. Mali Med. 2009;24(1):14-8. French. [PubMed: 19666388].

21. Stawicki SP, Seamon MJ, Kim PK, Meredith DM, Chovanes J, Schwab $\mathrm{CW}$, et al. Transthoracic echocardiography for pulmonary embolism in the ICU: Finding the "right" findings. J Am Coll Surg. 2008;206(1):427. doi: 10.1016/j.jamcollsurg.2007.06.293. [PubMed: 18155567].

22. Shopp JD, Stewart LK, Emmett TW, Kline JA. Findings from 12lead Electrocardiography that predict circulatory shock from pulmonary embolism: Systematic review and meta-analysis. Acad Emerg Med. 2015;22(10):1127-37. doi: 10.1111/acem.12769. [PubMed: 26394330]. [PubMed Central: PMC5306533].

23. Ryu HM, Lee JH, Kwon YS, Lee SH, Bae MH, Lee JH, et al. Electrocardiography patterns and the role of the electrocardiography score for risk stratification in acute pulmonary embolism. Korean Circ J.2010;40(10):499-506. doi:10.4070/kcj.2010.40.10.499. [PubMed: 21088753]. [PubMed Central: PMC2978292].

24. Szygula-Jurkiewicz B, Zebik T, Gasior M, Polonska A, Gierlotka M [Value of electrocardiography in the diagnosis of acute pulmonary embolism]. Pneumonol Alergol Pol.2003;71(3-4):132-8. Polish. [PubMed: 14587418].

25. Bakebe A, Kashongwe I, Mulenga C, Tshiasuma M, Kabengele B, Bisuta SF, et al. Pulmonary embolism: Epidemiological data and diagnosis in Kinshasa hospitals. Int J Tuberc Lung Dis. 2017;21(8):875-9. doi: 10.5588/ijtld.16.0418. [PubMed: 28786795].

26. Dogan H, de Roos A, Geleijins J, Huisman MV, Kroft LJ. The role of computed tomography in the diagnosis of acute and chronic pulmonary embolism. Diagn Interv Radiol. 2015;21(4):307-16. doi: 10.5152/dir.2015.14403. [PubMed: 26133321]. [PubMed Central: PMC4498425].

27. Albrecht MH, Bickford MW, Nance JJ, Zhang L, De Cecco CN, Wichmann JL, et al. State-of-the-art pulmonary CT angiography for acute pulmonary embolism. AJR Am J Roentgenol. 2017;208(3):495-504. doi: 10.2214/AJR.16.17202. [PubMed: 27897042].

28. Kumasaka N, Sakuma M, Shirato K. Clinical features and predictors of in-hospital mortality in patients with acute and chronic pulmonary thromboembolism. Intern Med. 2000;39(12):1038-43. doi: 10.2169/internalmedicine.39.1038. [PubMed: 11197786].

29. Kurakina EA, Duplyakov DV, Khokhlunov SM, Kozupitsa GS. Syncope in non-massive pulmonary embolism as a predictor of highrisk mortality. Ration Pharmacother Cardiol. 2012;8(2):158-62. doi: 10.20996/1819-6446-2012-8-2-158-162.

30. Kobayashi T, Nakamura M, Sakuma M, Yamada N, Sakon M, Fujita S, et al. Incidence of pulmonary thromboembolism (PTE) and new guidelines for PTE prophylaxis in Japan. Clin Hemorheol Microcirc. 2006;35(12):257-9. [PubMed: 16899938].

31. Grifoni S, Olivotto I, Cecchini P, Pieralli F, Camaiti A, Santoro $\mathrm{G}$, et al. Short-term clinical outcome of patients with acute pulmonary embolism, normal blood pressure, and echocardiographic right ventricular dysfunction. Circulation. 2000;101(24):2817-22. doi: 10.1161/01.cir.101.24.2817. [PubMed: 10859287].

32. Ribeiro A, Lindmarker P, Johnsson H, Juhlin-Dannfelt A, Jorfeldt L. Pulmonary embolism: One-year follow-up with echocardiography doppler and five-year survival analysis. Circulation. 1999;99(10):132530. doi: 10.1161/01.cir.99.10.1325. [PubMed: 10077516].

33. Agnelli G, Becattini C, Kirschstein T. Thrombolysis vs heparin in the treatment of pulmonary embolism: A clinical outcome-based meta-analysis. Arch Intern Med. 2002;162(22):2537-41. doi:10.1001/archinte.162.22.2537. [PubMed: 12456225]. 
34. Aymard T, Kadner A, Widmer A, Basciani R, Tevaearai H, Weber A, et al. Massive pulmonary embolism: Surgical embolectomy versus thrombolytic therapy-should surgical indications be revisited? Eur J Cardiothorac Surg. 2013;43(1):90-4. discussion 94. doi:10.1093/ejcts/ezs123. [PubMed: 22466693].

35. Azari A, Beheshti AT, Moravvej Z, Bigdelu L, Salehi M. Surgical embolectomy versus thrombolytic therapy in the management of acute massive pulmonary embolism: Short and long-term prognosis. Heart Lung. 2015;44(4):335-9. doi: 10.1016/j.hrtlng.2015.04.008. [PubMed: 26077690].

36. Kocea P, Mischke K, Volk HP, Eberle U, Ortlepp JR. [Prevalence and severity of pulmonary embolism are dependent on clinical and paraclinical parameters : Analysis of 1,943 consecutive patients with CT pulmonary angiography]. Med Klin Intensivmed Notfmed. 2017;112(3):227-38. German. doi: 10.1007/s00063-016-0144-1. [PubMed: 26931133].

37. Zhou H, Tang Y, Wang L, Shi C, Feng Y, Yi Q. [Risk factors associated with long-term mortality in patients with pulmonary embolism and the predictive value of Charlson comorbidity index]. Zhonghua Yi Xue Za Zhi. 2016;96(4):273-6. Chinese. doi: 10.3760/cma.j.issn.03762491.2016.04.009. [PubMed: 26879787]. 